\title{
FOREST MEASUREMENT ACCURACY ${ }^{1}$
}

\author{
BY HAROLD E. YOUNG ${ }^{2}$
}

\begin{abstract}
A scientific paper should be an addition to knowledge based on rigorous experimentation, proper analysis, and intelligent interpretation of results written in a format tailored for the subject matter. This paper will be primarily concerned with the philosophy and attitudes involved in the evolution and development of present forest mensuration accuracy levels as well as those that will be essential in altering our concepts of accuracy. Therefore it will not present the results of a particular experiment but will attempt to distill historical facts and professional observations. In order to do this I shall introduce some biographical information because my perspective has been molded by certain men, by specific research projects and by my primary occupation as a university professor - the search for the truth.
\end{abstract}

Thirty-two years ago I transferred to the University of Maine as a sophomore in forestry. This coincided with Dwight Demeritt's return as head of the Forestry Department and professor of forest mensuration. At that time he was preparing the revisions of the second edition of Forest Mensuration by Chapman and Demeritt. An excellent teacher, he introduced me to the subject and stimulated my natural interest in numbers. After a few years of field experience I was attracted to Duke because F. X. Schumacher, whose textbook I had first seen as an undergraduate, was there. I was one of many from the United States, Canada and other countries who recognized his genius and consequently studied under him. A peerless lecturer, an extraordinary forest scientist and a good friend, "Schu" has been my academic advisor since 1940. In the past twenty years Dwight, Grosenbaugh, Prodan, Strand and other illustrious mensurationists from many countries have expanded my perspective but none to the extent of Schumacher and Demeritt.

Teachers at all educational levels have a most serious charge for we are attempting to shape the minds of young people. This has been foremost in my mind during the past eighteen years in which approximately a thousand students have confronted $m e$ in one class after another. In my particular case I have been responsible for communicating the principles and methods of forest mensuration and their applications on scientific, professional and industrial levels. The principles of measurement are relatively constant but methods change frequently. My discussion of methods must always sound like criticism for all of our methods are of limited accuracy.

Every professor has favorite remarks that he makes over and over with successive classes often without realizing it. One of mine, of which I am

\footnotetext{
${ }^{1}$ Presented to the Conference on Wood Mcasurements, November, 1966, Fort William, Ont., Canada.

'Professor, School of Forestry, University of Maine, Orono, Maine.
} 
aware, is "If wood were as valuable as gold we would measure it with the same accuracy, but as matters stand our methods reflect the quantity and value of standing trees and the primary cut products". For me this is the nub of the entire issue. In any time period the basic question that faces us is: Are our measurement methods providing us with adequate accuracy for scientific, professional and industrial forestry required by this time period? I intend to devote the remainder of this paper to the exploration of that question.

Before doing so I would like to interject a relevant issue. There is only one professor of forest mensuration at a forest school so that direct communication with other mensurationists doesn't occur frequently; this is unhealthy in an academic sense. Consequently our silent doubts and personal unpublished research may lead us to an unwarranted point of view. In this context I freely admit that I now challenge the time honored definition of forest mensuration which refers to it as a "science". Politics has been called the art of the possible, and forest mensuration is, it seems to me, the art of the practical. I suggest that forest mensuration is not a science! That ought to awaken the sleepy and ignite the alert. Before you reject my point of view, let's return to the main issue and examine the concept of science and forest mensuration under considerable magnification.

There are several dictionary definitions of science that differ from one another only slightly. Each incorporates systematized knowledge and the discovery of general truth. The relationship between accuracy, precision and truth has been exquisitely stated by Conkling (1962) as follows:

"Precision has to do with the resolving power of the measuring device and is ordinarily indicated by the number of decimal places reported in the measurements made with the device. Accuracy has to do with how close a measurement is to some postulated true value. A measurement can be very precise, yet highly inaccurate."

Forest mensuration has exhibited interest in precision but has seemed rather contented with crude units of volume for all aspects of forestry. This inertia is my reason for classifying forest mensuration as an "art" rather than as a science.

The historical pattern of forest use and the development of forestry in most countries has been similar. In prehistoric times populations were small, people were primitive and forested areas, at least in the temperate zone, seemed endless. Early simple iron tools limited wood use to the natural solid and round-like form. As mechanization and industrialization increased more trees were cut and more varied uses were made of the tree bole including the use of wood in chip and fiber form. Serious concern for future wood requirements in terms of a rapidly expanding world population was evident at the recent World Forestry Congress. As a result of the rapid increase in harvesting readily available forests, the values of forest land, standing timber and the primary cut products are increasing rapidly. With increased values and increased quantities involved in sales there should be increased accuracy in mensurational methods. There is considerable concern 
by a few, and some improvement, but in general our mensuration methods have stagnated and do not reflect current market values.

An examination of our mensuration methods will support such a statement. We are currently using the same mensurational methods in scientific, professional and industrial forestry although the precision and accuracy requirements are seldom the same in all three. Yes, the board foot, the cord and the cubic foot are used in the same way in these three segments of forestry. These units are used in regression equations that have an aura of precision but the units and the errors in using them are unchanged. Sales involving both small and large sums of money use these units with results that are not equitable to both buyer and seller. Dbh is used in all aspects of forestry because it is "practical" but it may be the worst way to characterize tree size for scientific purposes.

The board foot is a measurement unit native to North America and to my knowledge fortunately confined to this continent. It is a very crude attempt to estimate the final sawed lumber from a log while it is round and uncut. There is no other industry or profession that attempts to measure the raw product in terms of the final product. The board foot continues to be used because it is now an established ingrained custom. When stumpage was $\$ 2.00$ per thousand board feet, sawed boards $\$ 20.00$ per thousand and mill output 3,000 board feet per day, there was little concern about the accuracy of the board foot as a unit of measure. Today stumpage, in some places, is already in excess of $\$ 25.00$ per thousand board feet, sawed boards sell for $\$ 120.00$ per thousand or more, and modern mills produce thousands of board feet per day. It is my belief that the board foot is not sufficiently accurate for industrial and professional purposes, and for scientific purposes it is altogether too crude to be used.

The cord is a much older unit of measurement than the board foot for John Evelyn mentions it in his Sylva (1670). The variable solid contents of rough and peeled stacked wood when using the cord as the unit of measurement are well documented and have been known for over sixty years (Graves 1906). Everything said earlier about the board foot applies equally to the cord. State, provincial and federal scaling regulations do not reduce errors; they merely crystallize them.

Cubic volume has long been considered THE best method of volume measurement but has been widely used only by such agencies as the U.S. Forest Service within the past fifteen years. Cubic volume is commonly determined by applying diameter and length measurements to standard formulae. According to Prodan (1965) the Smalian formula for volume determination came into use in 1804 or earlier and the Huber formula in 1785 or earlier. These are the two most commonly used formulae, and both assume that the $\log$ or bolt is the truncated frustrum of a paraboloid. There are a number of other formulae that are variations of these. Volume calculations of the stump often assume the shape of a cylinder and those of the unmerchantable top and branches that of a cone. The truth of the matter is that no segment of the tree bole conforms exactly to any geometric shape.

Two hundred years ago when wood and labor were cheap, only the lower part of the bole of large trees was used. This did approach the shape assumed 
by the two most commonly used formulae. With the increased value of wood there has been an increased use of the bole of felled trees as well as an increased use of smaller trees. With a total disregard for the increase in errors that occur by using these standard procedures on smaller material we have continued with the same methods.

Recently I completed the analysis of a study of $465 \mathrm{logs}$ of varying diameter, length and species comparing the volume as determined by the Smalian and Huber formulae with volume determined by displacement. A report of this study will be presented before Section 25, Growth, Yield and Forest Management, of the International Union of Forest Research Organizations in Munich in September 1967. Variations between the formulae and displacement increase with a decrease in diameter and an increase in length. Measurements taken every three inches of the diameter on four foot bolts still yielded differences between formulae and displacement of plus or minus 17 percent. The cubic foot has been used as the standard for determining variations in cord and board foot measurements, but it involves errors of measurement of the same magnitude as those being compared with it.

The bole, branches, stump and roots are irregular and bumpy due to natural reasons that cannot be controlled. Therefore it is completely untenable to assume that the segments of a tree conform to any geometric solid except for crude approximations. This rules out cubic foot measurement for scientific purposes and makes it highly questionable for professional and industrial purposes particularly where branches, stumps and roots may be involved.

Scaling, the actual measurement of wood for purchase, is a standard practice where the board foot and the cord are being used. Scaling is service function that is becoming increasingly costly as wages and salaries escalate. Increased effort is being made to limit scaling of logs and pulpwood to a single time with the hope that alternate methods of scaling will be developed to further reduce cost. Cubic measurement is very common in Europe where labor costs, in the past, have been low and stumpage values high. Cubic measurements have been discouraged on this continent for the opposite has been true, and it is well known that cubic measurement is more costly than either board foot or cord scaling.

As the proponent of the Complete Tree Concept, Young (1964) visualizes utilization of the entire tree. Because of the irregularities of the extremities of trees all three measurement units previously discussed would be eliminated. Thus we are encouraged to examine the possibilities of weight as the primary mensurational unit. Moisture content varies between species and between seasons of the year so that dry weight may be a better basis than fresh weight. Stemsrude (1964), Braathe and Okstad (1964) and others have developed reliable sampling methods to estimate dry weight from fresh weight. More economical and rapid methods are under consideration but they will not completely solve the problem. The size, shape and condition of primary forest products by species that can produce lumber, veneer stock, poles, piling and pulpwood now and for many years to come will play an important part in deciding wood values. Fresh weight can be determined with a small scalar error and a negligible human error. If the primary forest products 
are sorted by species into use and size classes, a reasonable basis for payment can be developed.

From a mensurational point of view, weight would introduce some new sources of error but it would eliminate the three older units and the errors that accompany them. Weight is being used as a basis of payment for sawlogs, pulpwood and chips in many mills. If we eventually accept weight as our primary unit of measurement for all aspects of forestry we will be encouraged to think in terms of total fiber production per acre per year which will alter many of our presently accepted forestry concepts.

Some mensurationists are not alarmed about the inaccuracies of volume measurement as they attach more importance to the distribution of trees by diameter classes as a more relevant basis for planning. This interest does bring us to the matter of tree and product measurements because such measurements are an important part in the calculation of volume of the cut product as well as the basis of estimating tree volume from tree dimensions.

Until recent years there has been more emphasis on the number of trees measured per plot and the number of plots measured per day than on the accuracy of the individual measurements. This implies that there is safety in large numbers and that errors are random and not biased. Just the opposite is too often true. We use the same measuring instruments in essentially the same manner for scientific, professional and industrial purposes. Height measuring instruments in common use have a human error of plus or minus four feet which can result in a height error of 5 to 10 percent. Errors in diameter measurements may be equally large due to improper use of instruments or incorrect height above ground. Irregularities in shape can contribute errors of the same magnitude with respect to the cut product.

Does all of this mean that we are in the midst of a measurement dilemma? Not at all. My critical remarks concerning tree measurement and volume methods are intended to bring current forest mensuration into sharp focus in terms of present and future values of our forests and forest products. If we will recognize the state of the art then we can direct our efforts for increased accuracies as follows:

1. Recognize that forest science, professional forestry and industrial forestry have different standards of accuracy in terms of allowable measurement error.

2. As a result of (1) different measuring units and procedures may have to be developed appropriate to each aspect of forestry. Simple means should be developed to relate one type of measurement to another.

3. Rapidly rising wages demand simplified, rapid and accurate means of measuring primary forest products.

4. There should be widespread professional recognition of the magnitude of measurement errors and their impact on forestry. Such mature recognition should lead to serious study of ways and means of improving forest measurements consonant with their use.

5. Forest mensuration should be transformed from an art to a science by continuous effort to seek the truth which is synonymous with accuracy, reliability and dependability. 


\section{BIBLIOGRAPHY}

1. BRAATHE, P. and T. OKSTAD. 1964. Trade of pulpwood based on weighing and dry matter samples. Meddelelser fra Det norske Skogforsoksvesen 72: 20:5-64.

2. CONKLING, R. M. 1962. Decimal correction error: An example in statistics Technometrics $4: 421-425$.

3. EVELYN, J Sylya 2nd ed.

4. GRAVES, H. S. 1906. Forest Mensuration. John Wiley and Sons. 458 p.

5. PRODAN, M. 1965. Holzmesslehre J. D. Sauerlander's Verlag, Frankfurt am Main. 644 p.

6. STEMSRUDE, F. 1964. Maling av virke etter vekt. Skogeieren 4:6-7.

7. YOUNG, H. E. 1964. The Complete Tree Concept. A Challenge and an Opportunity. Proc. Soc. Amer. For. 